\title{
AVALIAÇÃO DA COMPREENSÃO DE ESTUDANTES SOBRE O CÂNCER DE MAMA E DO COLO DO ÚTERO EM UM MUNICÍPIO DO MARANHÃO
}

\author{
EVALUATION OF STUDENTS' UNDERSTANDING ABOUT BREAST AND CERVICAL \\ CANCER IN A MUNICIPALITY OF MARANHÃO
}

\author{
Joselma Damiana Crovea Pinheiro ${ }^{1}$
}

Anne Karine Assunção Martins ${ }^{2}$

RESUMO: Introdução: $O$ câncer é a quarta causa de morte, resultando em um grande problema de saúde pública no mundo, e um dos tipos mais incidentes, nas mulheres, em todas as regiões brasileiras é o câncer de mama (29,7\%) e o câncer do colo do útero (7,4\%). Nos últimos anos, um grande número de casos vem aumentando, devido ao aumento da população, fatores de risco internos e externos juntamente as condições socioeconômicas. Objetivo: Avaliar o conhecimento das estudantes do ensino médio sobre os fatores de risco e prevenção dos cânceres de mama e colo do útero. Material e Métodos: Trata-se de um estudo descritivo transversal de campo por observação direta extensiva, questionário, realizado no município de São Bento -MA. Após consentimento dos responsáveis, pela assinatura do Termo de Consentimento Livre-Esclarecido (TCLE) e do Termo de Assentimento Livre-Esclarecido (TALE) pelas alunas foi aplicado o questionário. A coleta de dados foi realizada no período de maio a junho de 2019 e participaram do inquérito 202 adolescentes. Os dados coletados foram organizados em planilhas eletrônicas no Excel 2016 for windows, transportados para o programa GraphPad Prism 5.o e STATA i4.o e analisados por meio da estatística descritiva, avaliando a distribuição de frequência para cada questão. Resultados: Os resultados demonstram parcialidade de informação a respeito do câncer de mama e do colo do útero, justificada pela baixa renda, baixo nível de escolaridade dos pais e pouca procura dos profissionais da saúde. Conclusão: Portanto este estudo é fundamental para despertar as políticas públicas municipais e estaduais e fazer uma parceria entre as Secretarias Municipal e Estaduais para a disponibilização de recursos e estratégias na prevenção do câncer de mama e câncer de colo do útero, pois fica evidente enquanto essas alunas necessitam de informações.

Palavras-chave: Adolescentes. Conhecimento. Câncer do colo do útero. Câncer de mama. Fatores de risco.

ABSTRACT: Introduction: Cancer is the fourth leading cause of death, resulting in a major public health problem in the world, and one of the most incident types in women in all Brazilian regions is breast cancer $(29.7 \%)$ and cervical cancer $(7.4 \%)$. In recent years, a large number of cases has increased, due to the increase in population, internal and

\footnotetext{
Especialista em Metodologia de Ensino de Biologia e Química - FAVENI. E-mail: joselmaoo.jp@gmail.com.

${ }^{2}$ Doutora em Saúde Coletiva - UFMA: Email:anne.karine@ufma.br.
} 
external risk factors together with socioeconomic conditions. Objective: To assess the knowledge of high school students about risk factors and prevention of breast and cervical cancer. Material and Methods: This is a cross-sectional descriptive field study by extensive direct observation, questionnaire, conducted in the city of São Bento -MA. After the consent of those responsible, after signing the Informed Consent Term (TCLE) and the Informed Consent Term (TALE) by the students, the questionnaire was applied. Data collection was carried out from May to June 2019 and 202 adolescents participated in the survey. The collected data were organized in spreadsheets in Excel 2016 for windows, transferred to the GraphPad Prism 5.0 and STATA I4.0 software and analyzed using descriptive statistics, evaluating the frequency distribution for each question. ${ }^{3}$

Results: There sults demonstrate partial information about breast and cervical cancer, justified by low income, low level of education of parents and little demand from health professionals. Conclusion: Therefore, this study is essential to awaken municipal and state public policies and create a partnership between the Municipal and State Secretariats for the provision of resources and strategies in the prevention of breast cancer and cervical cancer, as it is evident while these students need information.

Keywords: Adolescents. Knowledge. Cancer of the cervix. Breast cancer. Risk factors.

\section{INTRODUÇÃO}

No decorrer dos anos, um grande número de casos de câncer vem sendo registrado no mundo, tornando-o um grave problema de saúde pública. O câncer é descrito como uma neoplasia genética que causa crescimento desordenado das células nos tecidos e órgãos do corpo dando origem aos tumores. Esses tumores são formados por grupos de células anormais, resultando em benignos ou malignos, e dependerá do organismo da pessoa ao ser influenciado por vários fatores de risco (KOCK KS, 2020; DE MATOS, 2017).

Além disso, essas neoplasias podem ser causadas por múltiplos fatores externos ou internos, ambos interligados ao organismo. Os externos envolvem o meio ambiente, os hábitos e costumes de vida de um indivíduo no meio cultural e social; e os internos, na maior parte das vezes, são geneticamente pré-determinados e estão relacionados à capacidade do corpo de se proteger das provocações externas (DE MATOS, 2017; INCA, 2017).

Dito isso, os fatores de risco podem comunicar-se de diversas formas iniciando o surgimento do câncer. De todos os acontecimentos, 80 a 90\% dos casos de câncer estão ligados ao ambiente. Os hábitos e estilo de vida do ser humano interferem nesse processo. A relação das causas internas (mutações) com as externas (dieta, cigarro, álcool etc.) pode 
aumentar a chance de desenvolver diferentes tipos de câncer (DE MATOS, 2017; INCA, 2017).

Dentre as neoplasias, o câncer de mama consiste em uma multiplicação de células anormais (mutantes) que se desenvolve no tecido da mama que formam um tumor. Uma neoplasia degenerativa que acomete principalmente o sexo feminino e raramente o sexo masculino. E, apesar da ocorrência de câncer de mama entre mulheres jovens ser baixa, no entanto, é necessário preveni-lo desde cedo (RODRIGUES et al.; DUGNO, et al. 2014).

A literatura relata que os principais fatores de risco para o câncer de mama são: ser do sexo feminino, a menarca precoce, o uso de contraceptivos hormonais, o sedentarismo, a inatividade física, o consumo de bebida alcoólica, o tabagismo, o consumo de alimentos ricos em gorduras, a obesidade, e os fatores genéticos e hereditários como histórico familiar de casos de câncer de mama (NGUNE, et al., 2020; ATWA, et al., 2019; DUGNO, et al. 2014).

Outra neoplasia de grande relevância é o câncer de colo de útero. O colo fica localizado na vagina na parte inferior do útero, é nessa região que se desenvolve uma multiplicação anormal das células formando um tumor. Esse tipo de câncer pode levar anos para evoluir e, nas fases primitivas em geral, apresenta-se de forma assintomática. É o terceiro tumor mais frequente no gênero feminino no Brasil (KOCK KS; PAULA, et al.,2020).

Esse fenômeno pode ocorrer devido aos fatores de risco para o desenvolvimento dessa neoplasia, um dos principais é o agente etiológico Papilomavírus humano (HPV). Além do mais, outros fatores de risco foram investigados como prática de sexo sem proteção, o início da atividade sexual precoce, múltiplos parceiros sexuais, o tabagismo, o uso de anticoncepcional oral, baixa ingestão de vitaminas e a alimentação inadequada (KOCK KS; PAULA, et al.,2020).

Então, uma forma de conscientizar a população e promover a atenção à saúde é desenvolver o trabalho de educação em saúde nas escolas. O processo de educação em saúde é uma estratégia importante para despertar mudança de comportamentos que proporcionem ou mantenham uma boa saúde, conscientizando os jovens sobre a prática do sexo seguro e o uso da vacina, autoexame das mamas, além de adotar mudanças de estilo de vida saudável. Tudo isso favorece o bem-estar do corpo, pois a grande maioria dos casos 
diagnósticos de doenças é por falta de prevenção, orientação, informação em não realizar os exames preventivos (AL-AZRI, et al., 2019; DE MATOS, 2017; GUETERRES, et al., 2017).

Dados epidemiológicos de 2019, revelam a incidência global dos diversos tipos de câncer registrados no mundo, destacando em mulheres: câncer de mama (29,7\%) e colo do útero $(7,4 \%)$, entre outros no Brasil. Esses tipos vêm causando mudanças na mortalidade e na morbidade juntamente com outros fatores socioeconômicos.

No Brasil, estima-se para os dois anos consecutivos, 2020-2022, a ocorrência de 625 mil casos novos de câncer a cada ano. Sendo o câncer de mama feminino a neoplasia que ocupa a primeira posição, como mais incidentes em todas as regiões brasileiras com ênfase na região Nordeste, (44,29 por Ioo mil), bem como o câncer do colo do útero (17,62/10o mil), o que aponta para a necessidade de pesquisas que esclareçam os fatores determinantes da alta incidência (SÁ, et al., 2018; INCA 2019).

Por isso, o objetivo do presente estudo foi avaliar o conhecimento das discentes do Ensino Médio sobre os fatores de risco e prevenção dos cânceres de mama e colo do útero em um município do Maranhão.

\section{MATERIAIS E MÉTODOS}

Esta pesquisa, trata-se de um estudo transversal, descritivo, realizado no município de São Bento, situado na microrregião da Baixada Maranhense, no Estado do Maranhão, localizado na latitude de $02{ }^{\circ} 4 I^{\prime} 45^{\prime \prime}$ sul e com longitude de $44^{\circ} 49^{\prime} 17 "$ oeste. O município tem uma população estimada de 40.736 pessoas com aproximadamente 2.013 meninos e 2.050 meninas de i5 a I9 (IBGE, 2010).

O público alvo foram alunas do sexo feminino entre 15 a 27 anos, estudantes do $\mathrm{I}^{\mathrm{o}}$ ao $3^{\circ}$ ano do Ensino Médio pertencentes a três escolas públicas no município de São Bento - MA. As escolas estaduais foram selecionadas logo após autorização dos diretores das respectivas escolas através da Declaração de Autorização da Pesquisa, junto a Secretaria de Educação Estadual.

Diante disso, foi feito o cálculo amostral a partir do levantamento populacional do número de alunas das escolas estaduais. Havia um total de 350 alunas entre 15-27 anos. 
Calculou-se o tamanho amostral que foi igual a 202, considerando heterogeneidade igual a $50 \%$, erro de $5 \%$ e nível de confiança de $95 \%$.

Os critérios de inclusão foram: ser aluna com idade entre 15-27 anos, do sexo feminino, estar devidamente matriculada nas instituições escolares, estar presente no ato da entrega do questionário e ter a autorização dos responsáveis das alunas menores de idade por meio da assinatura do Termo de Assentimento Livre-Esclarecido (TALE) e do Termo de Consentimento Livre-Esclarecido (TCLE), este último assinado pelos responsáveis e pelas alunas maiores de 18 anos.

Não só isso, mas, consideraram-se como critérios de exclusão: os responsáveis que não concordaram com a participação das alunas e as jovens maiores de 18 anos que também se recusaram a participar da pesquisa.

Antes de ser aplicado, foi executado um piloto entre os dias 7 à 9 de maio do ano 2019 com adolescentes de outro município, para verificação da adequação do questionário a fim de tornar mais claras as questões da temática investigada.

A seleção das alunas foi feita aleatoriamente por meio de sorteio do número da lista de alunos da escola. Essas alunas levaram o TALE e TCLE para casa e somente após consentimento dos responsáveis, a coleta de dados foi realizada.

Aplicação dos questionários ocorreu nos meses de maio e junho de 2019, durante as aulas cedidas pelos professores de Ciências, o questionário foi auto aplicado, com questões objetivas, de múltipla escolha, referente às atitudes, os hábitos, situação de saúde, informações sobre câncer de mama e câncer de colo do útero, à demografia e aos aspectos sociais das entrevistadas.

Segue abaixo as seguintes variáveis listadas no questionário:

(I) Aspectos demográficos e sociais - idade (anos), localidade da residência, zona (rural, urbana), raça /cor (branca, preto, amarela, parda), religião (católico, espírita, protestante, agnóstico, ateísta, acredito em Deus, mas não sigo nenhuma religião), renda econômica da família (menos de I salário-mínimo, até I salário-mínimo, de i a 3 salários mínimos) e o grau de escolaridade do pai mãe (anos de estudo). 
(2) Aspectos gerais da saúde - hábitos e atitudes (tempo nas atividades esportivas e exercícios físicos), uso de bebidas alcoólicas e cigarro, procura de serviços de saúde, o conhecimento sobre a sexualidade (início da atividade sexual, métodos contraceptivos e a I - menstruação).

(3) Aspectos sobre câncer de mama e câncer de colo do útero - conhecimento sobre sintomas, fatores de risco, prevenção do câncer de mama e de colo do útero, sobre autoexame da mama, preventivo, vacina contra o HPV e se já haviam sido vacinadas.

Após a coleta, os dados obtidos foram digitados em planilha do Microsoft Office Excel $2016^{\circledR}$ e a análise estatística mediante distribuição de frequência absoluta e relativa foi realizada no programa estatístico Stata versão i4.o (StataCorp LP, College Station, Estados Unidos) e programa GraphPad Prism 5.o.

A presente pesquisa foi aprovada pelo Comitê de Ética em Pesquisa da Universidade Federal do Maranhão (CEP/UFMA), parecer número: 1.804.507/2019.

\section{RESULTADOS}

Foram aplicados 202 questionários. As alunas entrevistadas tinham idade entre is a 27 anos, sendo a média \pm desvio padrão de idade de 17,2 \pm I,9 anos, destas 72,2\% (146) das alunas que tinham de 15 a 17 anos. Quanto à série escolar, 42,7 \% cursava o $3^{\circ}$ ano (Tabela I).

Quanto à análise da distribuição das características sociodemográficas, em relação à raça ou cor, $66 \%$ se consideram pardas e $29 \%$ das demais raça/cor. Em relação à renda familiar 78,71\% viviam com até I salário-mínimo. Quanto à religião das alunas 49,75\% eram católicas. No que refere ao grau de escolaridade dos seus progenitores, $35,64 \%$ do pai e $38,12 \%$ da mãe tinham ensino fundamental incompleto (Tabela I).

Tabela 1. Caracterização amostral das alunas do Ensino Médio que responderam ao questionário sobre câncer de mama e colo do útero em São Bento - MA, 2019.

\begin{tabular}{|l|c|c|}
\hline Variáveis/Categorias & $\mathbf{n}$ & $\%$ \\
\hline Idade (anos) & $\mathbf{2 0 2}$ & $\mathbf{1 0 0}$ \\
\hline I5 a I7 & 146 & 72,28 \\
\hline I8 a 20 & 43 & 21,29 \\
\hline 21 ou + & 13 & 6,44 \\
\hline Séries & 201 & 100 \\
\hline
\end{tabular}




\begin{tabular}{|c|c|c|}
\hline $\mathrm{I}$ o ano & 65 & 32,34 \\
\hline $2^{-}$ano & 86 & 42,79 \\
\hline Cor da pele & 201 & 100 \\
\hline Branca & 23 & $\mathrm{II}, 5$ \\
\hline Preta & 35 & 17,5 \\
\hline Amarela & Io & 5 \\
\hline Parda & 132 & 66 \\
\hline Total & 200 & 100 \\
\hline \multicolumn{3}{|l|}{ Renda } \\
\hline Menos de I salário mínimo & 3 & $\mathrm{I}, 49$ \\
\hline Até I salário mínimo & 159 & $78,7 \mathrm{I}$ \\
\hline De i a 3 Salários mínimos & 20 & 9,9 \\
\hline Mais de 3 salários mínimos & 3 & $\mathrm{I}, 49$ \\
\hline Ignorado & 17 & 8,42 \\
\hline Total & 202 & 100 \\
\hline \multicolumn{3}{|l|}{ Religião } \\
\hline Católico & 99 & 49,7 \\
\hline Espírita & 2 & $\mathrm{I}$ \\
\hline Protestante & 57 & 28,6 \\
\hline Agnóstico & $\mathrm{I}$ & 0,5 \\
\hline Ateísta & 2 & $\mathrm{I}$ \\
\hline $\begin{array}{l}\text { Acredito em Deus, mas não } \\
\text { sigo nenhuma religião }\end{array}$ & 38 & I9,I \\
\hline Total & 199 & 100 \\
\hline \multicolumn{3}{|l|}{ Escolaridade pai } \\
\hline $\begin{array}{l}\text { Ensino fundamental } \\
\text { incompleto }\end{array}$ & 72 & 35,6 \\
\hline $\begin{array}{l}\text { Ensino fundamental } \\
\text { completo } \\
\text { Ensino médio incompleto }\end{array}$ & $\begin{array}{l}17 \\
21\end{array}$ & $\begin{array}{c}8,4 \\
\text { Io,4 }\end{array}$ \\
\hline Ensino médio completo & $3 \mathrm{I}$ & 15,3 \\
\hline Ensino superior incompleto & 4 & $\mathrm{I}, 9$ \\
\hline Ensino superior completo & 9 & 4,4 \\
\hline Não sei & 48 & 23,7 \\
\hline Total & 202 & 100 \\
\hline \multicolumn{3}{|l|}{ Escolaridade mãe } \\
\hline $\begin{array}{l}\text { Ensino fundamental } \\
\text { incompleto }\end{array}$ & 77 & 38,12 \\
\hline $\begin{array}{l}\text { Ensino fundamental } \\
\text { completo }\end{array}$ & II & 5,45 \\
\hline Ensino médio incompleto & 30 & 14,85 \\
\hline
\end{tabular}




\begin{tabular}{|l|c|c|}
\hline Ensino médio completo & 43 & 21,29 \\
\hline Ensino superior incompleto & 7 & 3,47 \\
\hline Ensino superior completo & 13 & 6,44 \\
\hline Não sei & 21 & 10,4 \\
\hline Total & $\mathbf{2 0 2}$ & 100 \\
\hline
\end{tabular}

As demais foram avaliadas as atitudes e hábitos das alunas. Perguntou-se sobre a prática de exercícios físicos ou esportes: $51,5 \%$ responderam que não praticam e $48,4 \%$ já fizeram algum tipo de atividade física durante a semana (Tabela 2).

Para os dois conhecidos fatores de risco de câncer de mama, o tabaco e a bebida alcoólica, foram questionados se já usaram o tabaco. E o resultado obtido foi que 99,5\% (20I) responderam não fumar. Quanto ao consumo de bebidas alcóolicas, 20,7\% começaram a consumir entre 16 aos 18 anos, mas 57,9\% nunca consumiram nenhum tipo de bebida (Tabela 2).

Investigou-se sobre os aspectos gerais da saúde, para isso foi perguntado quando as alunas foram consultadas por um médico pela última vez: Os dados obtidos foram 23,1\% disse há menos de 2 semanas e 45,7\% de I mês até I ano sem ir ao médico (Tabela 3). Questionou-se se já haviam ido ao ginecologista: 77,1\% nunca foram ao ginecologista, e somente $22,8 \%$ disseram ter frequentado o ginecologista (Figura I).

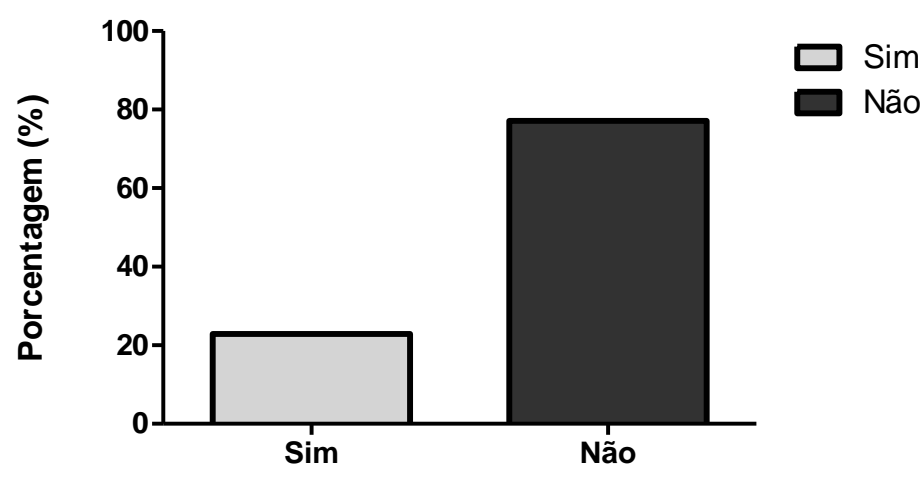

Figura r. Percentual de alunas que foram ao ginecologista.

Quando se inquiriu sobre o início da atividade sexual, 61,7\% (I2I) revelaram que ainda não iniciaram, 38,3\% (75) já iniciaram. E o método contraceptivo mais utilizado foi a camisinha com 61,80\% (Tabela 2). 
Tabela 2. Caracterização amostral dos aspectos gerais da saúde das alunas do Ensino Médio que responderam ao questionário sobre câncer de mama e colo do útero em São Bento - MA, 2019.

\section{Variável/Categorias}

Prática exercício físico

Sim

Não

Total

\section{Fuma cigarro}

Sim, diariamente

Não fumo atualmente

Total

Início do consumo bebidas alcoólicas

Menos de 12 anos

Entre 13 a 15 anos

I6 aos 18 anos

I9 aos 20 anos

Nunca consumi nenhum tipo de bebida alcoólica.

Total n

$\begin{array}{cc}96 & 48,4 \\ 102 & 51,5 \\ 198 & 100\end{array}$

$\%$

Idade menarca

$\begin{array}{lcc}9 \text { anos } & \text { I } & 0,5 \\ \text { IO anos } & 15 & 7,6 \\ \text { II anos } & 39 & 19,9 \\ \text { I2 anos } & 64 & 32,6 \\ \text { Outra idade } & 77 & 39,2 \\ \text { Total } & \text { 196 } & \text { 100 }\end{array}$

Iniciou a atividade sexual

$\begin{array}{lcc}\text { Não } & \text { I2I } & 61,7 \\ \text { Sim } & 75 & 38,3 \\ \text { Total } & \text { I96 } & \text { 100 } \\ \text { Idade que iniciou a atividade sexual } & & \\ \text { 8-9 anos } & \text { I } & 1,3 \\ \text { I2-I3 anos } & 5 & 6,6 \\ \text { I4-I5 anos } & 33 & 44 \\ \text { I6-I7anos } & 26 & 34,6 \\ \text { Mais de I7 anos } & \text { I0 } & 13,3 \\ \text { Total } & 75 & 100\end{array}$


Método contraceptivo

Camisinha

Pílula anticoncepcional ou injetável

Ligadura de trompas

Não uso nenhum método

Total

Quantidade de métodos contraceptivos

I métodos

Até 2 métodos

Até 3 métodos

Total

Com quem as alunas conversam sobre temas relacionados à sexualidade e saúde?

Amigos

Pais

Professores

Religiosos

Médico

Ninguém

Total

$\begin{array}{cc}55 & 6 \mathrm{I}, 8 \\ 26 & 29,2 \\ \mathrm{I} & \mathrm{I}, \mathrm{I} \\ 7 & 7,8 \\ 89 & \mathrm{IOO}\end{array}$

63

84

14,6

$\mathrm{I}, 3$

IOO

Questionou-se com quem as alunas conversam sobre temas relacionados à sexualidade e saúde, e $49 \%$ declaram que conversam com amigos enquanto $38,4 \%$ falam com os pais (Figura 2 e Tabela 2).

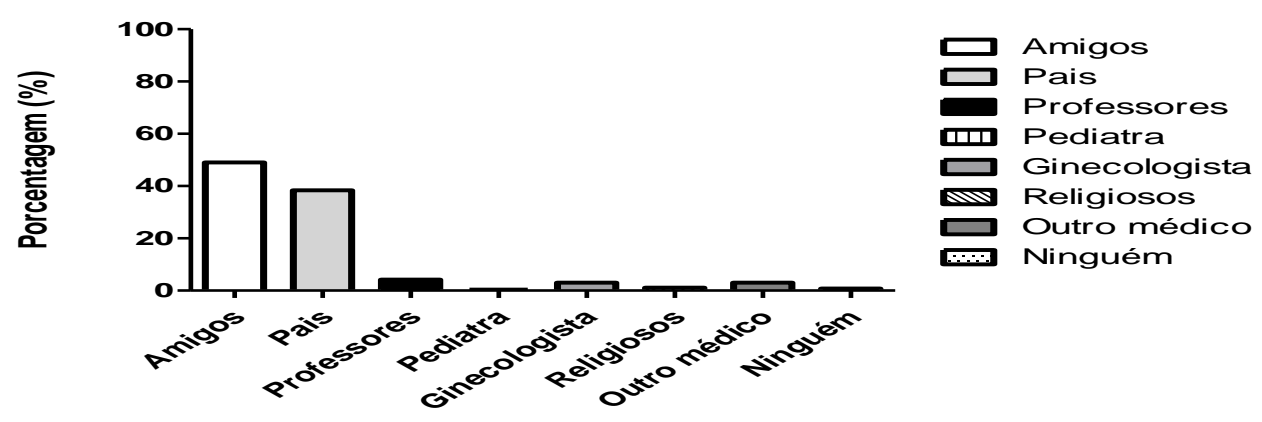

Figura 2. Grupos com os quais as entrevistadas conversam sobre sexualidade e saúde.

Sobre o conhecimento do câncer de mama $83,5 \%$ souberam o que era essa neoplasia e $84,9 \%$ afirmaram que sabiam que tem cura (Tabela 3 ). 
A respeito do autoexame das mamas, 72,2\% disseram não saber fazer o exame. A questão referente a quem pode ocorrer câncer de mama, 67,1\% das alunas acreditam que é somente em mulheres e $26,3 \%$ afirmaram que são nos dois sexos, tanto em homens quanto mulheres (Tabela 3).

Já sobre os fatores de risco para o câncer de mama, I8,o\% falaram que a história familiar de câncer de mama é um dos fatores de risco dessa neoplasia, 13,1\% o consumo de bebidas alcoólicas, I0,7\% exposição a radiações ionizantes em idade inferior a 35 anos e $58,0 \%$ outras causas (Tabela 4 ). Ao indagar se já haviam recebido informações sobre câncer de mama e prevenção do câncer de mama, 64,1\% responderam que sim e 35,9\% nunca receberam nenhuma informação (Figura 3 e Tabela 3).

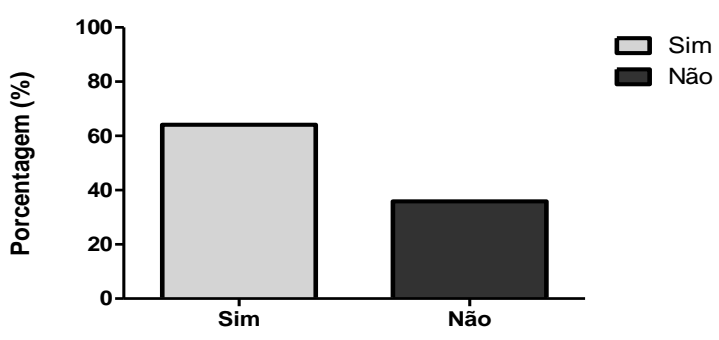

Figura 3. Percentual de alunas que receberam informações em campanhas.

Questionou-se a última vez que um enfermeiro ou médico fez o exame clínico das mamas das estudantes entrevistadas. O resultado foi o seguinte: $89 \%$ das alunas disseram que nunca fizeram o exame clínico e somente 6,5\% responderam menos de I ano atrás (Figura 4 e Tabela 3 ).

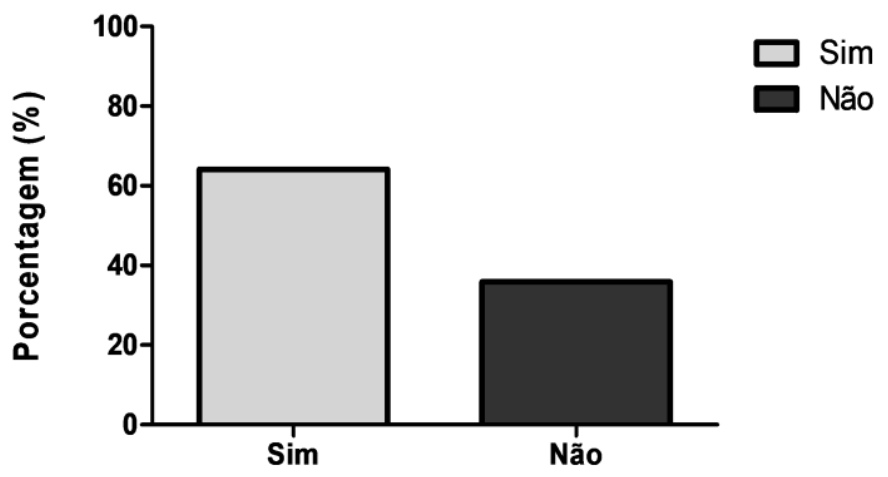

Figura 4. Percentual sobre o período de realização de exames clínicos das mamas. 
Já para o câncer de colo do útero, $58,5 \%$ das alunas já ouviram falar, mas não sabiam o que era esse tipo de tumor. Em relação aos sintomas do câncer do colo do útero $28,5 \%$ não souberam quais os sintomas para esse tipo de doença, outros $28,2 \%$ responderam perda de sangue anormal, 17,3\% infecção urinária e 13,7\% confirmaram ardência (Tabela 3).

Quanto a causa do HPV 61,2\% das discentes não sabem qual é o agente etiológico causador da neoplasia. Em referência a melhor fase para vacinação contra o HPV, 46,3\% da amostra afirmou que deve ser em qualquer idade, $34,5 \%$ antes do início da atividade sexual e 13,4\% após o início da atividade sexual (Tabela 3).

Inquiriu-se sobre qual tipo de exame que investiga o câncer do útero, apenas 37,6\% afirmaram o Papanicolau (preventivo).

Interrogou-se se alguma vez as entrevistadas já fizeram o exame preventivo do câncer do colo do útero na UBS (Unidade Básica de Saúde) ou clínica ginecológica: 89,5\% alegaram que não. Questionou-se o motivo de nunca ter feito o exame preventivo: $24,3 \%$ declararam nunca foram orientadas a fazer o exame e 17,2\% por vergonha (Tabela 3 ).

Ao questionar sobre a vacina contra o HPV, 86,8\% confirmaram que tomaram a vacina e $13,4 \%$ alegaram não terem tomado nenhuma dose. Quanto às doses que foram tomadas, 9,7\% apenas uma dose, 57,4\% duas doses, 28,7\% alegaram terem tomado três doses e 4,0\% não lembraram o número de doses (Tabela 3 ).

Sobre os fatores de risco para o câncer de colo do útero, 30,7\% responderam sexo sem proteção, I7,1\% múltiplos parceiros sexuais (Tabela 3).

Tabela 3 Caracterização amostral do conhecimento das alunas do Ensino Médio sobre câncer de colo do útero e câncer de mama em São Bento - MA, 2019.

Variável/Categorias

Sabe o que é câncer de colo do útero?

Nunca ouvi falar

Já ouvi falar, mas não sei o que é

Já ouvi falar e sei o que é n

I2

II7

71

37

$\%$

6

58,5

35,5

Quais os sintomas câncer de colo do útero

Perda de sangue anormal

28,2

Ardência

Infecção urinária

Ausência de menstruação

13,7

17,3

Continua...

I2, I 
Não sabe

Total

Qual o vírus?

SIDA

HPV

Hepatite

Herpes

Não sabe

Total
87

305

28,5

100

$\begin{array}{cc}3 & 1,5 \\ 62 & 31,6 \\ 5 & 2,5 \\ 6 & 3,0 \\ 120 & 61,2 \\ 196 & 100\end{array}$

Em qual fase da vida deve ser vacinada?

Em qualquer idade

46,3

Antes do início da atividade sexual

34,5

Após o início da atividade sexual

13,4

Depois da menopausa

$4, \mathrm{I}$

Não sabe

I,O

A partir dos 14 anos

0,5

Total

194

100

A partir de que fase deverá iniciar o rastreio do câncer do colo do útero?

Antes de iniciar a atividade sexual

Após o início da atividade sexual

6I

31,4

36,6

Depois dos 18 anos

2I, 6

$\mathrm{Na}$ menopausa

71

Não sabe

42

7,2

Total

6

3,0

194

100

Qual exame que investiga o câncer do colo do útero?

Prova de Mantoux

Cistoscopia

Papanicolau (preventivo)

Não sei

Total

$\begin{array}{cc}4 & 2,0 \\ 13 & 6,7 \\ 73 & 37,6 \\ 104 & 53,6 \\ 194 & 100\end{array}$

Já fez o exame preventivo?

$\begin{array}{lcc}\text { Sim } & \text { 2I } & 10,5 \\ \text { Não } & \text { I79 } & 89,5 \\ \text { Total } & 200 & 100 \\ & & \\ \text { Qual razão para NÃO ter feito? } & & 8,01 \\ \text { Não acha necessário } & 27 & 17,2 \\ \text { Tem vergonha } & 58 & \end{array}$


O plano de saúde não cobre a consulta

Está marcado, mas ainda não realizou

Nunca teve relações sexuais

Tempo de espera no serv. de saúde é muito

grande

O horário de funcionamento do serviço

Nunca foi orientado para fazer o exame

Não sabe quem procurar ou aonde ir

Dificuldades financeiras

Dificuldades de transporte

Dificuldades para marcar consulta

O serv. de saúde é muito distante

Outro

Total

$\begin{array}{ccc}9 & 2,6 & \\ 4 & \text { I,I } & \\ 76 & 22,5 & \text { Continua... } \\ 6 & \text { I,7 }\end{array}$

Frequência do exame de rastreio para o

câncer de colo do útero?

De 2 em 2 anos

$\begin{array}{cc}12 & 6 \\ 117 & 58,5 \\ 71 & 35,5 \\ 200 & 100\end{array}$

De ano a ano

6

De 5 a ro anos

3,5

Total

200

Você tomou a injeção para a vacina contra o HPV?

$\begin{array}{lcr}\text { Sim } & 174 & 86,8 \\ \text { Não } & 27 & 13,4 \\ \text { Total } & 201 & 100\end{array}$

Você tomou quantas doses da vacina?

I dose

2 doses

$\begin{array}{cc}17 & 9,7 \\ 100 & 57,4 \\ 50 & 28,7 \\ 7 & 4,0 \\ 174 & 100\end{array}$

Total 174

100

Como prevenir a transmissão do HPV?

Uso do preservativo (camisinha) nas

relações sexuais.

$\begin{array}{lll}\text { Evitar ter muitos parceiros ou parceiras } & 8 \mathrm{I} & 17,6\end{array}$

sexuais

$\begin{array}{lll}\text { Realizar a higiene pessoal } & 76 & 16,5\end{array}$

Vacinar-se contra o HPV $\quad 150 \quad 32,7$

Não sei 9

Total

458

IOO 
Fatores de risco para câncer colo do útero

$\begin{array}{lll}\text { Sexo sem proteção } & \text { I63 } & 30,7\end{array}$

Múltiplos parceiros sexuais $\quad 9 \mathrm{I}$

$\begin{array}{lll}\text { Pouca idade quando teve a I }{ }^{\circ} \text { relação sexual } & 54 & \text { IO,I }\end{array}$

Uso de anticoncepcional $\quad 54$ I0,I

Continua...

Falta de exercício físico

$\begin{array}{lll}\text { Ausência de atividade sexual } & 8 & 1,5\end{array}$

$36 \quad 6,7$

$\begin{array}{lll}\text { Tabagismo } & 27 & 5,0\end{array}$

Falta de vitaminas $\quad 22 \quad 4, \mathrm{I}$

$\begin{array}{lll}\text { Má alimentação } & 42 & 7,9\end{array}$

$\begin{array}{lll}\text { Durante o parto } & 8 & 1,5\end{array}$

$\begin{array}{lll}\text { Contato através da pele } & 20 & 3,7\end{array}$

Outro $\quad 5 \quad 0,9$

Total $\quad 530 \quad 100$

Câncer de mama

Sabe o que é câncer de mama?

Sim $168 \quad 83,5$

Não $\quad 33 \quad 16,4$

Total 201

Câncer é transmissível?

Sim

Não 107

II, 5

Não sei

$69 \quad 34,6$

Total

$199 \quad$ I00

Câncer tem cura?

$\begin{array}{lll}\text { Sim } & 169 & 84,9\end{array}$

Não $\quad 30 \quad 15,0$

$\begin{array}{lll}\text { Total } & 199 & 100\end{array}$

Sabe fazer o autoexame da mama?

Sim

$55 \quad 27,7$

Não

143

72,3

Última vez que um enfermeiro ou médico

fez exame clínico das mamas?

De I ano a $<$ de 2 anos

$\begin{array}{ll}17 & 8,5 \\ 5 & 2,5 \\ 178 & 89,0 \\ 194 & 100\end{array}$

3 anos ou mais

Nunca

IOO

Recebeu informações sobre câncer de mama e 194 prevenção do câncer de mama?

$\operatorname{Sim}$

125

64,4 
Não

35,6

Câncer de mama pode ocorrer em quem?

Somente em mulheres

$\begin{array}{cc}135 & 67, \mathrm{I} \\ \mathrm{I} & 0,5 \\ 53 & 26,3 \\ \mathrm{I} 2 & 5,9 \\ 201 & 100\end{array}$

Somente em homens

Nos dois sexos

Não sei

Total

Fatores de risco para câncer de mama

Consumo de bebidas alcoólicas $\quad 78$

Alimentos ricos em gorduras 53

Exposição a radiações ionizantes em idade

inferior a 35 anos

22

Obesidade (estar acima do peso)

Sedentarismo (não faz atividade física ou 49

esporte)

I- menstruação com pouco idade (menarca I9

precoce)

Menopausa tardia (depois dos 50 anos)

A nuliparidade ou o atraso na primiparidade

Primeira gestação após 30 anos

$15 \quad 2,5$

Tabagismo

I8 3,0

$42 \quad 7,0$

Terapia de reposição hormonal 13

$2, \mathrm{I}$

Uso de anticoncepcional

7,4

As pessoas acima de 50 anos

44

3,2

Alto consumo de laticínios

I9

3,7

História familiar de câncer de mama

22

Não sabe

107

18,0

3

0,5

Meios de comunicação pelos quais gostariam de receber informações?

Médico

Professor

109

36,8

Mídias (TV/rádio/internet/redes sociais)

53

I7,9

Em relação aos meios de comunicação pelos quais gostariam de receber informações, 43,5\% disseram pediatra ou clínico geral e $36,8 \%$ professor em escola (Figura 5 e Tabela 4).

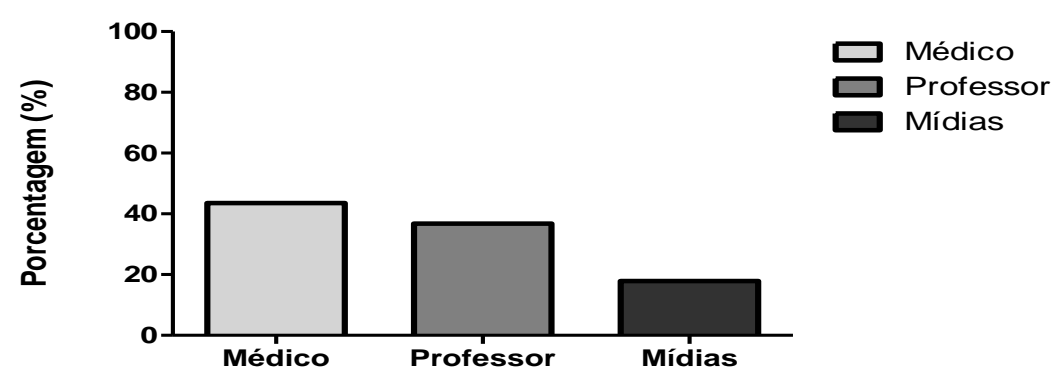




\section{Figura 5. Percentual sobre os meios de comunicação para receber informações. DISCUSSÃO}

Ao analisar os resultados, apurou-se que $27 \%$ das alunas entrevistadas tem mais de I8 anos. Esse é um problema que vem sendo agravado no decorrer dos anos, devido aos altos níveis de repetência, causado pela baixa qualidade do ensino, as altas taxas de defasagem idade/série ou interrupção causada muitas vezes por uma gravidez precoce, na qual jovens mães deixam seus estudos para trabalhar para sustentar seus próprios filhos, e há outras ainda que desistem dos estudos por conta da procura de um emprego informal para ajudar na renda familiar, gerando assim uma alta evasão escolar (IBARRA, 2018).

Segundo dados do Instituto Brasileiro de Geografia e Estatística (IBGE, 2010), o Ensino Médio abrange preferencialmente a faixa etária dos 15 aos 19 anos, e os resultados desta pesquisa revelaram que as alunas se encontram com idade muito superior para este nível/etapa de ensino (SOUSA, et al., 2018).

Por isso, são necessárias políticas que incentivem as adolescentes a retornar e completar seus estudos, para adquirir condições de inserir-se no mercado de trabalho, contribuindo para uma renda melhor e menor índices de gravidez não planejada (SOUSA, et al., 2018).

Dito isso, os fatores socioeconômicos influenciam os aspectos relacionados à saúde e à educação. Os dados evidenciam que $78,7 \%$ das famílias das discentes tem em torno de I salário mínimo e isso acarreta dificuldades em acesso a bens e à saúde de qualidade. Normalmente, a baixa renda está associada um nível menor de escolaridade dos membros da família, como observado no grau de escolaridade dos progenitores: 35,6\% dos pais têm ensino fundamental incompleto, bem próximo do percentual das mães $(38,1 \%)$ (MOHAMMED AL-AZRI, et al., 2019).

Dessa forma muitas alunas não têm acesso adequado principalmente à prevenção $e$ promoção à saúde, bem como suas famílias, resultados semelhantes foram encontrados por Ferreira (2018), investigando a adesão à vacina contra o HPV em município próximo de São Bento - MA.

Um exemplo disso é, a baixa escolaridade dos pais pode limitar o acesso às notícias, o diálogo com suas filhas sobre sexualidade, a consulta com médicos, a compra de diversos medicamentos e anticoncepcionais comprometendo, assim, o autocuidado com a saúde. 
Em função disso, notou-se que $49 \%$ das discentes declararam que conversam com amigos e apenas $38,4 \%$ com os pais sobre a saúde e sexualidade (PAULA, et al., 2020).

Não só isso, mas as pessoas de baixa renda e de nível de escolaridade inferior, muitas vezes, quando vão descobrir casos de doenças, já estão em estados avançados, o que prejudica um bom prognóstico, expandido a morbidade relacionada ao tratamento. Quanto menor o nível de escolaridade familiar, maiores as desinformações da população sobre a IST, cânceres de mama e de colo do útero (NGUNE, et al.,2020; AL-AZRI, et al., 2019).

Por conseguinte, em relação às crenças e religiões, a maioria professa alguma religião cristã $(78,3 \%)$. Coutinho et al. (2014) enfatiza que jovens que seguem alguma religiosidade tem menores chances de ter um filho na adolescência do aqueles que não têm nenhuma religião, além disso ele argumenta que as mulheres protestantes têm ainda pequena possibilidade de vir a ter uma criança durante a adolescência, indicando que as igrejas protestantes desestimulam a prática do sexo antes do casamento em suas doutrinas, influenciando mudança de comportamento das jovens fieis, baseando-se no votos de castidade e virgindade a fim de se preservarem até o casamento.

Nesse sentido, percebeu-se que $51,5 \%$ das alunas não praticam exercício físico e somente $48,4 \%$ o fazem durante a semana. A inatividade física e o sedentarismo são fatores de risco para o câncer, pois estão diretamente ligados ao aumento de peso, consequentemente, contribui para a obesidade (AL-AZRI, et al., 2019).

Diante disso, o fator de risco para câncer de mama e colo do útero bem caracterizado na literatura é o tabagismo. No cigarro são encontradas substâncias químicas, citotóxicas, mutagênicas e carcinogênicas. Neste trabalho, no entanto, 99,5\% das alunas entrevistadas não fumam, sendo considerado um bom hábito na prevenção do câncer (AL- AZRI, et al., 2019).

Destaca-se um outro fator de risco investigado nesta pesquisa - o consumo de bebida alcoólica - que está relacionado ao aumento proporcional do câncer de mama, ou melhor, quanto mais ingerir tais bebidas, maiores serão as chances de aparecimento da doença: 20,7\% das adolescentes de 16 a 18 anos passaram a fazer o uso de bebidas alcoólicas elevando, assim, o risco de desenvolver manifestação pré-câncer como displasias (INCA, 2019). 
Sobre a investigação relacionada à saúde das alunas, foi questionado há quanto tempo foi a última ida ao médico ou ginecologista (23,1\% há menos de 2 semanas). Esse dado foi alarmante, pois $77,1 \%$ das alunas nunca foram ao ginecologista. Nos estudos realizados por Al-Azri, et al. (2019) certos tipos de câncer podem ser curados e tratados se forem diagnosticados precocemente.

O corpo da mulher na adolescência passa por várias modificações, surgem dúvidas sobre I- menstruação, o início da atividade sexual, a gravidez precoce, o aborto espontâneo que são alguns dos desafios e incompreensões acerca do seu corpo. Por isso, um profissional da saúde é muito imprescindível, pois ele orientará sobre as mudanças que estão ocorrendo, sobre as Infecções Sexualmente Transmissíveis (IST's), uso de preservativos nas relações sexuais, uso de anticoncepcional, prevenção de várias doenças inclusive o câncer (AL-AZRI, et al., 2019).

Entretanto, muitos pais por falta de conhecimento acabam evitando de levar suas filhas a um profissional da saúde, pois acreditam que isso influenciará o início da vida sexual das suas filhas. $\mathrm{Na}$ verdade, os pais são as pessoas mais indicadas para orientá-las da importância da consulta ao ginecologista (PAULA, et al., 2020).

O gênero feminino é o principal fator de risco para o desenvolvimento de câncer de mama. A menarca precoce é vista como fator de risco principalmente para as adolescentes que têm a primeira menstruação aos 12 anos ou antes disso. Das alunas que responderam ao questionário, 52,5\% têm idade da menarca menor ou igual a 12 anos (INCA, 2017).

O início da vida sexual precoce, antes dos dezesseis anos, aumenta o risco para o desenvolvimento de câncer do colo do útero e $44 \%$ adolescentes afirmaram que iniciaram sua vida sexual entre I4 -I5 anos (PAULA. et al.,2020; AL-AZRI, et al., 2019).

Nesse período os hormônios ainda estão desorganizados e a cérvice ainda não está formada completamente e quanto mais cedo ocorrer a primeira relação sexual, maior será a possibilidade de exposição ao HPV e lesões no colo uterino e que podem expandir-se no decorrer dos anos se essas jovens não estiverem acompanhadas por profissionais de saúde. O controle desses fatores contribui para minimizar os riscos de câncer de mama e câncer do colo do útero (PAULA. et al., 2020). 
$\mathrm{Na}$ literatura, o uso dos contraceptivos orais ainda é discutindo pelo fato de estimular o sexo sem proteção, abrindo uma grande oportunidade das mulheres se contaminarem com IST's, inclusive o HPV e o vírus da imunodeficiência humana (HIV) favorecendo o aparecimento do câncer cervical. Indo em oposição a essa linha de raciocínio, $61,8 \%$ das discentes utilizam a camisinha nas relações sexuais o que contribui para minimizar o risco de contrair as IST's, principalmente o HPV (PAULA, et al., 2020). E 29,21\% das alunas utilizam pílula anticoncepcional ou injetável (NGUNE, et al., 2020).

Mas também existem aquelas que não usam nenhum método de proteção. Nesta pesquisa elas correspondem a 7,8\%. Paula, et al., (2020) destacam que informações precárias, relações permeadas por iniquidades de gênero, assim como a falta de organização e modo de funcionamento dos serviços de saúde afetam a eficácia das práticas de prevenção e promoção da saúde.

Nesse sentido, o câncer de mama pode ser considerado, atualmente, um problema de saúde pública devido à crescente incidência e índices de letalidade (COUTO, et al., 2017). Dentre as iniciativas para prevenção mais exitosas está o movimento Outubro Rosa, que visa chamar a atenção da população a respeito do câncer de mama em mulheres (MORAIS, et al, 2018).

Essa iniciativa, integrada pelo INCA, foi implantada no SUS em 2010, tornando-se parte do programa nacional de controle do câncer de mama de acordo com Couto, et al., (2017), fato este observado na pergunta do questionário sobre ter recebido informações por meio de campanhas: $64 \%$ responderam afirmando que sim.

A este programa, bem como outros, atribuímos os resultados de que $83,58 \%$ das alunas sabem o que é câncer de mama, 84\% afirmaram que câncer de mama tem cura e a maioria (53,7\%) também afirma que o câncer não é transmissível - apesar de existir alguns vírus oncogênicos, isto é, capazes de produzir câncer que podem ser transmitidos através do contato sexual, de transfusões de sangue ou de seringas contaminadas utilizadas, por exemplo, para injetar drogas (DE MATOS, 2017; INCA, 2017).

De acordo com INCA, (2019) situação de mulheres com história de câncer de mama com parentesco de $\mathrm{I}^{\mathrm{o}}$ grau (corresponde de 5 a $10 \%$ dos casos), principalmente em idade jovem, encontra-se associado ao aparecimento de mutações em genes transportados da família, sobretudo os dois genes BRCAr e BRCA2. 
Preocupa-nos que $13,9 \%$ das alunas afirmaram que já houveram casos na família, como em mães, tias, primas e avós. Por isso o risco cumulativo dessas discentes e dos familiares de adquirir o carcinoma é maior do que na população em geral.

A respeito do autoexame das mamas, 72,2\% responderam não saber fazer o exame, $67 \%$ afirmam que somente mulheres podem ter esse tipo de câncer, e 26,3\% responderam que pode ocorrer em ambos os sexos. Destaca-se que a probabilidade masculina de ter câncer de mama é I\% conforme afirma INCA (2019).

Esses dados nos mostram um grave problema: o autoexame é primeiro passo para a detecção precoce e rastreamento do câncer de mama, ele detecta o câncer ainda no início, momento mais adequado para o prognóstico, e saber informações a respeito do câncer de mama, seus métodos de diagnóstico e prevenção são fundamentais para controle da doença. Mais agravante ainda foi a resposta sobre a última vez que as alunas realizaram um exame das mamas com um profissional da saúde: $89 \%$ relataram que nunca foi realizado este exame (ATWA, et al., 2019).

O exame clínico das mamas é usado como método tanto diagnóstico quanto de rastreamento, é um complemento essencial na investigação diagnóstica de doenças mamárias e o primeiro método de avaliação diagnóstica na atenção primária (ATWA, et al., 2019).

Como rastreamento, é entendido como um exame de rotina feito por profissional de saúde treinado - geralmente enfermeiro ou médico - realizado em mulheres saudáveis, sem sinais e sintomas suspeitos de câncer de mama. Ao contrário de seu papel consagrado como método diagnóstico, o rastreamento por meio do exame clínico é alvo de grande controvérsia na literatura científica, sendo recomendado a partir de 20 anos (NASCIMENTO, et al., 2021).

No questionário, na pergunta sobre os fatores de risco para o câncer de mama, todas as alternativas são fatores de risco, assim, esperava-se que as alunas marcassem todas as alternativas para comprovar que conheciam de fato os fatores de risco dessa doença, mas isso não aconteceu.

Alternativas como consumo de bebidas $(13,1 \%)$ e histórico familiar (18,0\%) tiveram os maiores percentuais. $\mathrm{O}$ número de alternativas marcadas por questionário foi de apenas 
o a 2 (53\%) fatores de risco, demonstrando a deficiência de conhecimento a respeito do câncer de mama entre as alunas do Ensino Médio.

Sobre o conhecimento do câncer de colo do útero, os resultados da sondagem não foram tão promissores: $58 \%$ já ouviram falar, mas não sabem o que é, não sabem definir os sintomas dessa doença, a maioria não sabe qual o vírus associado a maioria dos casos (61\%), responderam erradamente sobre a fase da vida que devem ser vacinadas, não sabem qual o exame de rastreio (53\%), nem sua frequência.

No entanto, $86,8 \%$ já foram vacinadas, $57 \%$ com duas doses. Muito provavelmente, o percentual de meninas vacinadas se deve às campanhas realizadas em parceria com escolas e secretarias de saúde, como bem abordado por Ruas, et al. (2017) que observaram uma drástica queda na cobertura vacinal no município de Amparo - SP quando a escolha da distribuição da vacina ocorreu somente nas UBS's daquele município.

Para a investigação dos fatores de risco foi feita a mesma abordagem para o câncer de mama. Todas as alternativas eram também fatores de risco, mas os mais assinalados foram sexo sem proteção $(30,7 \%)$ e múltiplos parceiros sexuais (17,1\%). Quanto à frequência de opções assinaladas, foi muito baixa por questionário, 87\% escolheram de I a 4 fatores de risco.

As ações educativas que visam melhorar o conhecimento e incentivar a vacinação devem ser pautadas nos seguintes pontos: no significado do vírus e do câncer de colo do útero; na vacinação contra o HPV; no rastreamento, diagnóstico e tratamento do câncer; na prevenção das IST’s; participação e autonomia do público-alvo para a adoção de comportamentos saudáveis (SANTOS, 2017).

O que se observou é que uma parte significativa das alunas do Ensino Médio em São Bento - MA são vacinadas, mas não sabem por que estão sendo vacinadas, as informações a respeito do vírus, prevenção, rastreio e diagnóstico são limitadas.

Um resultado a se destacar foi a respeito das informações sobre câncer de mama e câncer de colo do útero: $96,5 \%$ desejam receber informações principalmente pela via de comunicação como médicos (43\%), professores (36\%) e mídias (17,9\%).

Essas atividades precisam ser desenvolvidas ainda mais nos ambientes escolares, uma vez que é lá onde os jovens permanecem a maior parte do seu dia. Somando-se à escola, deve haver a presença do sistema de saúde, com iniciativas de educação em saúde 
para levar comunicação clara, contínua, consistente e voltada aos diferentes grupos da comunidade escolar, sejam meninos e meninas, tanto do Ensino Fundamental como no Médio, bem como pais, professores, gestores e funcionários a fim de sensibilizar e informar sobre a temática por meio de campanhas, materiais educativos, mídias sociais, e outras tecnologias modernas (AL-AZRI, et al., 2019).

\section{CONSIDERAÇÕES FINAIS}

Diante do exposto nos resultados, foi notável que as informações e conhecimento a respeito do câncer de mama e, principalmente, do câncer de colo do útero são parciais entre as alunas do Ensino Médio em São Bento - MA.

Pela análise dos dados, podemos afirmar que a maioria se expõe a fatores de risco que deveriam ser identificados e evitados, tomando atitudes e hábitos de saúde para ter melhor qualidade de vida. No que diz respeito à busca pelo sistema de saúde, grande parte nunca foi ao ginecologista, não sabe fazer o autoexame das mamas e um dado que chama atenção é que nenhum profissional da saúde realizou o exame clínico nas mamas das alunas entrevistadas.

Destacam-se também dados positivos, como a maior parte das alunas não fumarem, não consumirem bebidas alcoólicas e serem vacinadas contra o HPV.

Este estudo se mostra importante para nortear as políticas públicas municipais e estaduais pois, tanto por parte da Secretaria de Educação como pela Secretaria de Saúde, é fundamental a disponibilização de recursos e estratégias na prevenção do câncer de mama e do câncer de colo do útero.

Em vista disso, os resultados e discussões apresentados indicam ser necessário abrir espaço para aprofundar as práticas e campanhas de educação em saúde no ambiente escolar de forma permanentemente, pois quando aliados à escolha de um método de ensino adequado, promoverão a qualificação, a formação e, principalmente, a construção de um sujeito crítico, saudável física e mentalmente, detentor de uma identidade social bem estruturada.

Algumas limitações desta pesquisa foram o não aprofundamento no estudo de cada fator de risco individual; a investigação de outros hábitos como a prática de atividades físicas; bem como detalhar a qualidade de horas de estudo e os fatores de proteção. 
Desse modo, espera-se que a presente investigação possa motivar pesquisas futuras nessa temática. Portanto, para novos estudos, sugere-se projetos de extensão que proponham estratégias educativas, que possam trabalhar diretamente esses resultados com as alunas nas 3 escolas do município de São Bento - MA, assim como aprofundar o estudo dos fatores de risco e proteção.

Enfim, através deste estudo, percebeu-se a necessidade da transmissão de informações referente ao tema, que é de extrema importância para as populações, posto que, durante realização da pesquisa, foi notório o quanto essas alunas são carentes de informações relacionadas à temática do câncer de mama e câncer de colo do útero.

\section{REFERÊNCIAS}

AL-AZRI, Mohammed et al. Knowledge of Cancer Risk Factors, Symptoms, and Barriers to Seeking Medical Help among Omani Adolescents. Asian Pacific Journal of Cancer Prevention, [s. l.], v. 20, p. I-I2, 7 ago. 2019. DOI I0.31557/APJCP.2019.20.12.3655.

COUTINHO, Raquel et al. Religião, religiosidade e iniciação sexual na adolescência e juventude: lições de uma revisão bibliográfica sistemática de mais de meio século de pesquisas. R. bras. Est. Pop., Centro Universitário de Maringá, Programa de PósGraduação em Promoção da Saúdezor7, v. 31, ed. 2, p. 1-34, 2014.

COUTO, Vanessa Brito Miguel et al. "Além da Mama”: o Cenário do Outubro Rosa no Aprendizado da Formação Médica. Revista Brasileira de Educação Médica, v. 4I, p. 30-37, 2017.

DE MATOS, Talita. Educação em saúde visando a prevenção do câncer de mama e próstata em estudantes da rede pública. 2017. 1-6o p. Trabalho de Conclusão de Curso (Licenciatura em Ciências da natureza-Biologia) - Graduada, Instituto Federal de Educação, Ciência e Tecnologia Fluminense - campus Centro, 2017.

DUGNO, Matheus et al. Perfil do câncer de mama e relação entre fatores de risco e estadiamento clínico em hospital do Sul do Brasil. Revista Brasileira de Oncologia Clínica, [s. l.], v. Io, ed. 36 , p. I-7, I4 out. 2021.

FERREIRA, Rosangela. Vacinação contra o papiloma vírus humano: conhecimento e adesão de alunas de escolas da rede pública de ensino em São Luís - Maranhão. 2017. I-56 f. Trabalho de Conclusão de Curso (Graduação de Enfermagem) - Bacharel em Enfermagem, Universidade Federal do Maranhão, 2017. Disponível em: https://referenciabibliografica.net/a/pt-br/ref/abnt. Acesso em: 8 ago. 2021. 
GUETERRES, Évilin et al. Educación para lasaludenel contexto escolar: estudio de revisión integradora. Enfermería Global, [s. l.], v. 16, ed. 2, 28 mar. 2017. DOI https://doi.org/ro.6or8/eglobal.16.2.2358or.

IBARRA, Rosa. Prevenção da gravidez na adolescência através de intervenção educativa em uma localidade do município de Santa Quitéria - CE. 2018. 30 f. Trabalho de Conclusão de Curso (Curso de Especialização em Saúde da Família, modalidade semipresencial, Universidade Aberta do SUS (Una-SUS) - Universidade Federal do Ceará, 2018. Disponível em: https://ares.unasus.gov.br/acervo/handle/ARES/20226. Acesso em: 22 ago. 2021.

INSTITUTO Brasileiro de Geografia e Estatística: IBGE. [S. l.], 2oro. Disponível em: https://cidades.ibge.gov.br/. Acesso em: or out. 2021.

INSTITUTO Nacional de Câncer José Alencar Gomes da Silva. Estimativa 2020: incidência de câncer no Brasil / Instituto Nacional de Câncer José Alencar Gomes da Silva. - Rio de Janeiro: INCA, 2019.

INSTITUTO Nacional de Câncer José Alencar Gomes da Silva. Estimativa 2018: incidência de câncer no Brasil / Instituto Nacional de Câncer José Alencar Gomes da Silva. - Rio de Janeiro: INCA, 2017.

MORAES, Adivanete et al. Monitoramento das Ações Educativas: Outubro Rosa. Visão Universitária, [S. l.], v. I, p. I-9, 2018.

NASCIMENTO, Vanessa Maria et al. Exame preventivo: Conhecimentos e práticas sobre a perspectiva de adolescentes um relato de experiência. Research, Society and

Development, [s. l.], ano 2021, v. Io, ed. 8, p. I-8, io jul. 202I. DOI https://doi.org/ıo.33448/rsd-vioi8.17078.

NGUNE, Irene et al. Biopsychosocial risk factors and knowledge of cervical cancer among young women: A case study from Kenya to inform HPV prevention in SubSaharan Africa. PloS one, v. I5, n. 8, p. e0237745, 2020.

OLIVEIRA, Marcela et al. Utilização de uma tecnologia educativa no processo de ensinoaprendizagem de adolescentes sobre saúde sexual e reprodutiva: relatos de experiência: Anais do XXIII Workshop de Informática na Escola (WIE 2017). VI Congresso Brasileiro de Informática na Educação (CBIE 2017), [s. l.], ano 2017, p. I-9, 2017. DOI 10.5753/cbie.wie.2017.118. Disponível em: https://www.brie.org/pub/index.php/wie/article/view/7229/o. Acesso em: 5 jul. 2021.

PAULA, Alice et al. Conhecimento de enfermeiros na prevenção do câncer de colo uterino em adolescentes. Revista Atenas Higeia, [s. l.], ano 2020, v. 2, ed. 2, p. I-8, abril/2020 2020.

RODRIGUES, Juliana et al. Uma análise da prevenção do câncer de mama no Brasil. Ciência \& Saúde Coletiva, [s. l.], v. 20, ed. Io, p. I-I4, 2015. DOI: 10.1590/1413812320152010.20822014. 
RUAS, Bruna et al. Estratégia e adesão da vacinação contra HPV no município de Amparo, São Paulo, Brasil. Revista Saúde em Foco, [s. l.], ano 2017, ed. 9, p. I-II, 2017.

SÁ, Fabia et al. Perfil epidemiológico da mortalidade por câncer do colo do útero no Brasil entre 2000 e 2015. Revista olhar científico, [s. l.], v. 4, ed. I, p. I-23, jan/jul 2018.

SANTOS, Carolina. Percepção das adolescentes sobre a infecção do hpv e seus fatores de risco: reflexão sobre a utilização das tic no controle da transmissão do hpv. 2017. 1-73 f.

Dissertação (Mestre em Promoção da Saúde.) - Mestre, Centro Universitário de Maringá, Programa de Pós-Graduação em Promoção da Saúde, 2017. Disponível em:

http://rdu.unicesumar.edu.br/handle/12345

SOUSA, Carolina et al. Fatores preditores da evasão escolar entre adolescentes com experiência de gravidez. Cadernos de Saúde Coletiva, Rio de Janeiro, ano 2018, p. I-1o, 2018. DOI I0.1590/1414-462X20180002046I. 